\title{
Território e Territorialidades Tupiniquim
}

\section{Gilsa Helena Barcellos*}

Resumo: $O$ artigo discute os efeitos devastadores do desenvolvimento industrial sobre a vida de povos indígenas no Espírito Santo a partir da chegada da Aracruz Celulose S.A. no território indígena, no final dos anos 1960 . O estudo tem como base pesquisa sobre a população tupiniquim analisando o processo de desterritorialização/reterritorialização que erodiu o modo de vida indígena. O estudo mostra como essa população, empenhada há 42 anos em uma luta incansável pela recuperação territorial, reafirma a importância do lugar como foco de resistência ao projeto hegemônico global. A pesquisa mostra como, ao longo desse processo, os tupiniquim vão construindo a sua história de R-existência, dando importante contribuição ao movimento contra a globalização hegemônica.

Palavras-chave: Tupiniquim; território; poder; movimentos sociais; r-existência.

\begin{abstract}
The paper discusses the devastating effects of the establishment of Aracruz Celulose S/A plant in the indigenous areas of the State of Espirito Santo. It is based on research done by the author among Tupiniquim people, following the processes which led them to a struggle that goes through for more than forty-two years now. As the paper says, that is the way tupiniqins are making their own history: fighting for their existence and against hegemonic globalization.
\end{abstract}

Keywords: Tupiniquim; territory; power; social movements; r-existence.

\section{Introdução}

O presente artigo tem como objetivo analisar a importância do território para a reprodução do modo de vida indígena tupiniquim; ${ }^{1}$ o comprometimento desse modo de vida com a chegada do capital agroindustrial ao seu território; e o seu processo de R-existência ${ }^{2}$ e luta pela recuperação territorial.

\footnotetext{
* Assistente Social. Mestre em Psicologia Social pela Universidade Federal do Espírito Santo. Doutora em Geografia pela Universidade Federal de Minas Gerais. Professora da Escola Superior de Ciências da Santa Casa de Misericórdia de Vitória (EMESCAM). Endereço postal: Av. Nossa Senhora da penha, 2.190, Santa Luiza, Vitória, Espírito Santo, CEP: 29045.402. Endereço eletrônico: gilsahb@terra.com.br.

${ }^{1}$ O presente artigo foi escrito usando como referência a tese de doutorado da autora, intitulada 'Desterritorialização e R-existência Tupiniquim' (BARCELLOS, 2008).

2 Porto-Gonçalves sugere uma relação entre resistência e existência - R-existência: "mais do que resistência, o que se tem é R-existência, posto que não se reage simplesmente a ação alheia, mas, sim, que algo pré-existe e é a partir dessa existência que se R-existe. Existo, logo resisto. R-existo." (PORTO-GONÇALVES, 2006, p. 165).
} 
A compreensão da trajetória territorial contemporânea dos tupiniquim - nos últimos 42 anos, desde a chegada da multinacional Aracruz Celulose S.A. (ARCEL) ao seu território - no Espírito Santo exige que se retome a colonização do Brasil, que de fato determinou um lugar de subalternidade aos povos indígenas no processo de construção da sociedade brasileira. Os movimentos de desterritorialização e reterritorialização vivenciados a partir da chegada desse empreendimento aprofundam essa subalternidade, produzindo a erosão do seu modo de vida e comprometendo substancialmente os seus códigos culturais. No entanto, contrariamente à violência a que esse povo foi submetido, escreve-se uma belíssima história de "R-existência", particularmente nas últimas quatro décadas, levando-o a reconquistar, em 2007, parte do território que estava sob o controle da agroindústria de celulose. Essas contradições do processo de dominação social e de resistência indígena são o foco da pesquisa.

Para a realização do estudo, foram adotados vários procedimentos metodológicos articulados entre si e basicamente centrados na revisão da literatura e na pesquisa empírica. Especificamente, o trabalho empírico abrangeu diferentes técnicas de coleta de dados, como a observação participante, a história oral e as entrevistas semiestruturadas individuais e de grupo. A metodologia qualitativa auxiliou a compreensão das implicações do modelo agroindustrial da ARCEL sobre a vida do povo tupiniquim. Em cada estágio da pesquisa, uma técnica ou outra ganhou maior expressão auxiliada nas referidas circunstâncias pelas demais. A história oral, vista como recurso complementar à documentação histórica e os dados agregados, no caso das indígenas tupiniquim, estabeleceu-se como um instrumento estratégico, pois os tupiniquim caracterizam-se pela cultura de tradição oral. Por isso, a história oral foi uma das metodologias mais utilizadas na pesquisa de campo, junto com a observação participante. E, por fim, a consolidação dos achados da pesquisa foi estruturada a partir de cinco categorias: território, lugar, gênero, etnia e identidade. Parte da análise desse material coletado na pesquisa será apresentada em seguida.

\section{Considerações sobre o Território e a Territorialidade Tupiniquim}

\subsection{Os Tupiniquim ${ }^{3}$}

Segundo Sánches (2001), o tipo de relação que cada etnia tem estabelecido com a sociedade maior tem sido determinante para definir sua existência. Algumas têm achado a maneira de manter a essência de sua cultura, outras recriam formas de transmissão dos seus valores às novas gerações. "A maioria está em meio a um processo acelerado de mudanças e o que se vê são perdas progressivas de suas terras [...]" (SÁNCHES, 2001, p. 7, tradução nossa).

Mas quem são os indígenas na contemporaneidade? Discorrer sobre identidades de povos indígenas apresenta-se como uma tarefa difícil, particularmente pelo fato de a imensa maioria das comunidades indígenas ter contato, por meio da

\footnotetext{
${ }^{3}$ De acordo com Bechara, "por convenção internacional de etnólogos, está há anos acertado que, em trabalhos científicos, os etnônimos que não sejam de origem vernácula ou nos quais não haja elementos vernáculos, não são alterados na forma plural, sendo a flexão indicada pelo artigo plural: os tupi, os nambiquara, os caiuá, os tapirapé, os bântu, os somali etc" (2006, p. 129).
} 
história, com a chamada sociedade branca, que tem modificado as estruturas tradicionais de sua cultura. Em decorrência disso, para Sánches (2001), não se pode falar da existência de indígenas "puros" que tenham conservado sua cultura original intacta, "[...] pois é evidente que uma relação que se iniciou há 500 anos tenha dado os seus frutos". Os Tupiniquim, ${ }^{4}$ na atualidade, nas palavras de Sánches, "são uma mistura de tradição, adaptação, imposição e recriação". Na sua história se entrecruzam raízes ancestrais, imposições do conquistador e estratégias de sobrevivência. "Antes de tudo, são povos vivos que se encontram em uma permanente dinâmica, porém se veem obrigados, hoje mais do que nunca, em virtude do fenômeno da globalização, a estabelecer relações com o branco" (SÁNCHES, 2001, p. 7, tradução nossa).

Sobre a origem dos Tupiniquim: a partir da sistematização e articulação de dados arqueológicos e linguísticos, a literatura majoritariamente afirma que os Tupiniquim integram a família Tupinambá, que, por conseguinte, é pertencente ao tronco linguístico Tupi-Guarani. Sua presença no Espírito Santo foi registrada pelos cronistas do século XVI. Historiadores capixabas afirmam que essa presença antecedeu a chegada dos portugueses. Segundo Moraes (1986), quando os portugueses aportaram, encontraram, no que hoje se configura o território capixaba, os Tupiniquim, os Tamoio, os Botocudo e os Goitacás. Os Tupiniquim tiveram sua sesmaria identificada pela Coroa Portuguesa em 1610. No entanto, essa só foi demarcada no século XVIII. De acordo com Maracci (2008), desde então os Tupiniquim se estabeleceram no que hoje se configuram os municípios de Aracruz, Fundão, Serra, Vitória e trechos dos municípios de Cariacica, Santa Leopoldina, Ibiraçu e Linhares, conformando uma extensão territorial de aproximadamente 200 mil hectares. No entanto, com as investidas do Império e, depois, da República, os Tupiniquim chegaram à década de 1960 com um território restrito ao município de Aracruz, com uma extensão de aproximadamente 30 mil hectares (MARACCI, 2008), abrigando 36 aldeias indígenas. Com a chegada da ARCEL, em 1967, os indígenas tiveram o seu território reduzido a uma faixa de 40 hectares. ${ }^{5}$ A densa Mata Atlântica deu lugar ao monocultivo de eucalipto em larga escala, transformando profundamente a paisagem e conformando novas relações de poder naquilo que um dia havia sido o território Tupiniquim.

\subsection{Território e territorialidades Tupiniquim}

[...] as sociedades constroem o seu mundo e a sua cultura através do território [...]. Assim, o território não é um dado circunstancial. Ele é vital e parte integrante da dinâmica das coletividades. A vida não é um movimento desterritorializado. Entendido como espaço produzido pela sociedade, o território é obra coletiva e,

\footnotetext{
${ }^{4}$ Tupiniquim, Tupin-i-ki, nome Tupi, quer dizer "Tupi do lado" ou "vizinho lateral".

${ }^{5}$ Nessa quantidade de terras não está incluída a Aldeia de Comboios (com uma extensão territorial de 2.300 hectares) pelo fato de essa ser uma península de solo arenoso, inadequado para o plantio de eucalipto. Em decorrência disso, ela permaneceu sob o controle dos indígenas.
} 
em si mesmo, manifestação de poderes. A construção do território, através de relações sociais, por si só, passa a significar o estabelecimento de fronteiras de natureza variada - entre pessoas e coisas (HISSA, 2002, p. 40).

Ao analisar a experiência territorial Tupiniquim, é relevante considerar alguns eventos históricos como pressupostos profundamente articulados e implicados na conformação da sua condição territorial atual. O primeiro deles diz respeito à sua historicidade territorial, compartilhada com outros povos indígenas, de profundas interferências produzidas pelo outsider (o Outro) desde a conquista; o segundo pressuposto refere-se ao surgimento do Estado-nação ocorrido no século XIX; e o terceiro e último pressuposto refere-se à importância do território para o autorreconhe-cimento Tupiniquim e para o seu reconhecimento pelo outsider:

i) A historicidade do território Tupiniquim - Inserir historicamente as mudanças territoriais ocorridas permite melhor compreender a dinâmica atual do território Tupiniquim e, por conseguinte, a sua territorialidade. Para Barel, por exemplo, analisar as transformações sociais a partir da dinâmica territorial conforma-se num exercício bastante interessante, "[...] pois a mudança social é em parte esta: a vida e a morte dos territórios. Estes territórios têm uma história" (apud HAESBAERT, 2005, p. 170). Nesse caso, a mudança social é tratada como um movimento de territorialização-desterrritorializaçãoreterritorialização (TDR). ${ }^{6}$ Lembra o autor que o advento da modernidade ${ }^{7}$ e do capitalismo, que afetam e subordinam os lugares mais distantes, são, por essência, desterritorializantes: "De uma certa maneira, pode-se representar a modernidade como o lento aparecimento de códigos desterritorializantes que engendram o seu contrário, isto é, a necessidade de novos territórios". (HAESBAERT, 2005, p. 170). Soma-se à modernidade e ao capitalismo o fenômeno da globalização. De acordo com Haesbaert (2005) e lanni (2003), a globalização corrobora o processo já iniciado de desterritorialização: "Aos poucos, ou de repente, o mundo se torna grande e pequeno, homogêneo e plural, articulado e multiplicado". (IANNI, 2003, p. 91). Simultaneamente à globalização, "[...] dispersam-se os pontos de re-ferência, dando a impressão de que se deslocam, flutuam, perdem". (Ibidem, p. 92). Para o sociólogo, a globalização busca "desenraizar as coisas, as gentes e as ideias", levando-as a adquirir uma identidade genérica: "Tudo tende a desenraizar-se". (IANNI, 2003, p. 94). Dessa forma, os sujeitos coletivos que buscam consolidar os seus laços identitários e territoriais pre-existentes

\footnotetext{
${ }^{6}$ Haesbaert propõe a formação da tríade conceitual: "territorialização-desterritorialização-reterritorialização" (TDR): "para apreender distinções dentro de um amplo continuum que se estende desde a territorialização mais [...] enraizada dos territorialismos, como predominava entre as sociedades tradicionais [...] até a desterritorialização mais extrema [...] em que os indivíduos perdem seus laços com o território [...]" (2005, p. 170).

${ }_{7}$ Para Guatarri (2000, p. 169), os mitos da modernidade - o progresso e a revolução - buscam estabelecer a vocação da humanidade para o novo, empurrando-a em direção à sociedade ideal -, por isso a ruptura com o anterior e, por conseguinte, a sua desterritorialização.
} 
estão na contramão da história hegemônica, transformando-se em focos de resistência local à dinâmica global. Por isso a importância da historicidade territorial, uma vez que, mesmo que povos indígenas busquem se mover territorialmente de forma mais autônoma, os adventos de caráter global, como Colonialismo, Modernidade, Capitalismo e Globalização, desejam ardorosamente subordiná-los às suas lógicas: "O evento da desterritorialização está para além das corporações transnacionais e mercados monetários, incorporando "grupos étnicos, lealdades ideológicas e movimentos políticos que atuam crescentemente em moldes que transcendem fronteiras e identidades territoriais específicas" (IANNI, 2003, p. 95).

Haesbaert retoma a importância da inserção histórica do território: "Voltando a este atributo mesmo que consideremos o território ou a territorialidade um constituinte inerente a todo grupo social, ao longo de toda sua história, é imprescindível diferenciá-lo na especificidade de cada período histórico" (2004, pp. 82-3). Aqui não se buscará especificar os diversos períodos históricos da vida territorial Tupiniquim, mas chamar a atenção para a relevância dessa história marcada por distintos, porém articulados, modelos de dominação implantados no Brasil: Período Colonial, Império, Estado-nação, República, Ditadura Militar, Estado Neoliberal e a Globalização Econômica. "Os povos foram, na maior parte do tempo, territorialmente, definidos de acordo com a geografia colonial, e declarados independentes sob esta base" (SANTOS, 2001, p. 320). No período colonial, por exemplo, depois de capturados, índios eram vendidos e escravizados. Por "sorte", aqueles cristianizados eram transformados em força de trabalho (do capital mercantil) para alimentar, por meio da extração de matéria-prima, o capital industrial que estava nascendo na Europa (SOUSA FILHO, 2004).

As grandes interferências registradas pela história - à exceção do movimento migratório dos Tupi-Guarani no período pré-colombiano $-^{8}$ foram produtos de imposições de terceiros e não de escolhas por parte das populações indígenas. Dessa forma, as interferências externas determinaram, sobremaneira, a qualidade e a quantidade territoriais e, por consequência, a sua territorialidade. ${ }^{9} \mathrm{O}$ processo de territorialização, desterritorialização e reterritorialização (TDR) Tupiniquim foi "geografado" (PORTO-GONÇALVES, 2001) por interesses estranhos aos seus - bem como pelas suas r-existências - conformando um ambiente territorial engendrado por conflitos políticos e concepções de mundo radicalmente diferentes da sua.

ii) $\mathrm{O}$ Estado nacional - $\mathrm{O}$ segundo pressuposto diz respeito à criação do Estado-nação brasileiro, ocorrida no século XIX, constituindo-se num

\footnotetext{
${ }_{8}^{8}$ Migliazza (1982) e Schmitz (2006) sustentam a ideia de que os Tupi-Guarani aparecem por volta de 5 mil anos antes do presente (AP), entre os rios Ji-Paraná (MT) e Aripuanã (RO), tributários do rio Madeira. Próximo à Era Cristã, teriam migrado para o sul. Depois, parte, os Guarani, concentrou-se no sul, e a outra parte, os Tupinambá, dispersou-se ao longo da costa sudeste e nordeste brasileira.

${ }^{9}$ Identificam-se quatro grandes rupturas na experiência territorial Tupiniquim: a primeira ocorre com chegada dos conquistadores, no século XVI; a segunda se deu na primeira metade do século XIX, com o fim do Regime Sesmarial e a Lei de Terras; a terceira ocorre com a Constituição de 1891, quando as terras devolutas ficam sob a responsabilidade dos Estados; e o quarto ocorre no final de 1960, com a chegada da ARCEL.
} 
paradoxo, porque, ao mesmo tempo em que se buscou construir a autonomia do Brasil frente à Portugal, impôs-se internamente como um modelo de dominação político-territorial. "O território era a base, o fundamento do Estado-Nação, que ao mesmo tempo o moldava" (SANTOS, 1996, p. 15). Definia-se como um território nacional, de preferência contínuo e inteiro, separado de outros territórios por fronteiras claramente definidas, dominando a totalidade de seus habitantes (HOBSBAWM, 1990). A territorialização do Estado-nação, nos países do Sul (países em desenvolvimento ou países do Terceiro Mundo), ${ }^{10}$ promoveu a desterritorialização de povos nativos e gerou a quebra de autonomia de territórios autóctones, porque impôs uma ordem nacional de território estranha à ordem local. A hegemonia territorial do Estado nacional subordinou territórios pré-existentes no seu interior. Dizia List (1885) que um território e uma população extensos são condicionantes para uma "nacionalidade normal". "Uma nação restrita em população ou território, especialmente se possuir uma língua distinta, pode apenas possuir uma literatura estropiada, e instituições estropiadas para promover sua arte e ciência" (LIST apud HOBSBAWM, 1990, p. 42). Continua o autor: "Um Estado pequeno não pode, em seu território, promover à perfeição os vários ramos da produção". Por isso, foi necessário o alistamento compulsório dos povos a uma nação e, por conseguinte, à lógica mercantilista, que alimentou o capitalismo industrial europeu. List se apoiou em Molinari, quando esse, anteriormente, afirmava que "a fragmentação da humanidade em nações é útil na medida em que desenvolve um princípio extremamente poderoso de competitividade econômica." (LIST apud HOBSBAWM, 1990, p. 40).

A legitimidade para a constituição de uma nação residia na sua capacidade de conquista: "Não há nada como um povo imperial para tornar uma população consciente da sua existência coletiva como povo [...]. A conquista dava prova darwiniana do sucesso evolucionista enquanto espécies sociais" (HOBSBAWM, 1990, pp. 49-50). Ainda de acordo com Hobsbawm, a equação "nação = Estado = povo" e especialmente povo soberano, nas palavras do próprio autor, vinculou subitamente a nação ao território, que constituía a estrutura e a definição dos Estados. Na gênese do Estado-nação está a concepção europeia de homogeneização cultural e ideológica que determinou um de seus mais importantes objetivos: dar continuidade ao processo civilizatório iniciado pelos colonizadores. A "[...] ideia de Estado-nação foi introduzida na maioria das sociedades do Sul através da conexão colonial montada nos ombros do conceito da responsabilidade civilizadora do homem branco (o 'fardo' do homem branco)" (NANDY, 2000, p. 90). A homogeneização cultural, a demarcação do espaço territorial, a regularização do espaço econômico e a oficialização das instituições políticas buscaram garantir uma base uniforme de referências para o universo público, o qual se estendia para os espaços da vida privada,

\footnotetext{
${ }^{10}$ De acordo com Santos et al., "Como símbolo de uma construção imperial, o 'Sul' exprime todas as formas de subordinação a que o sistema capitalista mundial deu origem: expropriação, supressão, silenciamento, diferenciação, desigualdade etc. $\mathrm{O}$ 'Sul' significa a forma de sofrimento humano causado pela modernidade capitalista [...]" (2004, p. 23).
} 
abrindo-se a possibilidade da criação do mito de uma identidade nacional. No entanto, observa Hobsbawm que, no movimento mundial europeu de constituição do Estado-nação, diferenças eram aceitas quando subalternizadas:

A heterogeneidade nacional dos Estados-nações foi aceita sobretudo porque parecia claro que as nacionalidades pequenas, e especialmente as pequenas e atrasadas, só tinham a ganhar fundindo-se em nações maiores e fazendo através destas sua contribuição para a humanidade. 'A experiência', disse Mil, articulando o consenso de observadores sensíveis, 'prova que é possível para uma nacionalidade fundir-se e ser absorvida por outra'. Para os inferiores e atrasados, isso seria um enorme ganho [...] 'do que azedar, em suas rochas, o arcaísmo semisselvagem dos tempos passados, remoendo-o em sua pequena órbita mental, sem participação ou interesse no movimento geral do mundo' (HOBSBAWM, 1990, p. 46).

O surgimento do Estado-nação foi marcado, de acordo com Sousa Filho (2004), pelo individualismo jurídico. Não mais é possível que outros interesses - os coletivos - se interponham entre a relação indivíduo e Estado. Impõem-se, dessa forma, as mesmas leis e rearranjos administrativos instituídos por todo o território. Isso transforma os direitos essencialmente coletivos em individuais fundamentados pela propriedade privada. A partir dos direitos individuais e da incorporação da condição de trabalhador livre - condição sine qua non para o desenvolvimento do capitalismo - perde-se o direito à identidade étnica e, por conseguinte, o direito ao território coletivo. Atemorizava os condutores da ideia do Estado-nação que as sociedades pré-modernas interferissem negativamente na consolidação de uma nação monoétnica. Essa ideologia vinculou-se ao fenômeno do nacionalismo, que reivindicou um espaço geográfico para o uso exclusivo dos membros da comunidade nacional. Para Santos (2001), nos séculos XIX e XX (até 1960), a concepção monoétnica tornou possível a "conversão da dominação étnica em nacionalismo". Segundo Schimit, "o nacionalismo étnico lutou para transformar o grupo étnico em uma categoria mais abstrata e politizada, a 'nação', e então estabelecer a última como único critério de legitimação do Estado" (apud SANTOS, 2001, p. 316). Pouco a pouco, o conceito de Estado moderno conseguiu minar e se sobrepor às outras noções de organização política que ainda restavam em regiões do Sul, com o argumento de que esses exemplos de primitivismo precisavam ser civilizados e integrados à sociedade nacional:

Portanto, se o único nacionalismo historicamente justificável era aquele ajustado ao progresso - isto é, aquele que alargava, e não restringia a escala de operação humana na economia, na sociedade e na cultura - qual podia ser a defesa dos povos pequenos, das línguas menores e das tradições menores, na grande maioria dos casos, a não ser uma expressão da resistência con- 
servadora ao avanço inevitável da história? Os pequenos povos, línguas e culturas ajustavam-se ao progresso apenas no caso de aceitarem o status subordinado a alguma unidade maior ou caso se retirassem da batalha para se tornar um repositório de nostalgia e de outros sentimentos (HOBSBAWM, 1990, p. 53).

A falsa ideia de um Estado para todos deu ao projeto moderno a legitimidade de praticar a violência contra inúmeras sociedades autóctones, destruindo os seus modos de vida, seus sistemas de subsistência e sua diversidade cultural, em nome do bem-comum, da segurança nacional, do progresso e da civilidade. À subalternidade étnica acopla-se a subalternidade territorial e vice-versa. Para Santos (2001), o Estadonação está preso à lógica técnico-funcional das redes desterritorializantes, ou seja, constitui, por excelência, um exemplo da ambiguidade moderna do processo de "des-reterritorialização", por ser dotado de auto-organização e estruturado sobre um espaço constituído de memórias coletivas. Para se constituir como tal, sugou experiências territoriais primeiras (preexistentes), não para a produção de um território híbrido, mas para silenciá-las no processo de sua construção:

iii) A importância do território para os tupiniquim - O terceiro e último pressuposto refere-se à importância do território para o autorreconhecimento e para o seu reconhecimento pelo outsider. Qual é o nível de importância do território para a reprodução do modo de viver tupiniquim e para a reconstrução e reafirmação da sua identidade étnica? A vida tupiniquim e sua história são movimentos territorializados. O território é possuidor de uma memória, de registros que articulam e testemunham a presença tupiniquim. O território, como biodiversidade mais cultura, impõe-se como condição para o seu existir. Pode-se dizer por meio das palavras de Hissa, que os tupiniquim "[...] constroem o seu mundo e a sua cultura através do território [...]. Assim, o território não é um dado circunstancial. Ele é vital e parte integrante da dinâmica [dessa] coletividade" (2002, p. 40). Nele, essa população tece as relações determinadas pelas suas dimensões material e simbólica. A partir da sua complexidade interna, o território define um limite, uma alteridade: a diferença entre o "nós" (insiders) e os "outros" (outsiders) (SOUZA, 2005).

Tomando de empréstimo as expressões de Guattari (2000), os agenciamentos territorializados de enunciação da vida tupiniquim se manifestam das mais variadas e intensas formas, seja no campo simbólico-cultural, seja na dimensão econômicopolítica. Nessa perspectiva, a divisão sexual do trabalho e os papéis sociais tupiniquim são complexos eventos territorializados:

[...] as relações sociais, as trocas econômicas e matrimoniais não eram muito discerníveis do conjunto da vida daquilo que propus chamar de agenciamentos territorializados de enunciação. Através de semiotização, de sistemas de representação 
e de práticas multirreferenciadas, tais agenciamentos conseguiam fazer cristalizar segmentos complementares de subjetividade, extrair uma alteridade social pela conjugação da filiação e da aliança, induzir uma ontogênese pessoal pelo jogo das faixas etárias e das iniciações, de modo que cada indivíduo se encontrasse envolto por várias atividades transversais coletivas [...] (GUATTARI, 2000, p. 127, grifo nosso).

Se Guatarri dá relevância à subjetividade que impregna e é impregnada pelo território, Souza destaca a sua base material: "O espaço social, delimitado e apropriado politicamente enquanto território de um grupo, é suporte material da existência [...] e, nessa qualidade, indispensável fator de autonomia" (2005, pp. 107-8). Nessa perspectiva, observa-se que, ao analisar a experiência territorial tupiniquim, as gigantescas interferências externas à sua vida territorial afetaram-na radicalmente, tanto na sua dimensão subjetiva/simbólica quanto material/física. Em períodos anteriores, o território - compreendido como algo em constante processo de ressignificação - era dotado de condições que Ihes permitiam maior autonomia econômico-política. ${ }^{11}$ Diante dos novos acontecimentos, a territorialidade teve de ser profundamente ressignificada. Apesar das investidas contra o seu território reafirma-se, cada vez mais, o poder do vínculo territorial tupiniquim que desvela o espaço, investido de valores materiais, simbólicos, espirituais, éticos e afetivos: "Pertencemos a um território, não o possuímos, guardamo-lo, habitando-lo (sic), impregnando-nos dele [...]" (BONNEMAISON e CAMBRÈZY apud HAESBAERT, 2004, p. 73). A territorialidade indígena tupiniquim atesta-se pela memória coletiva da sua relação com o território, dando-lhe profundidade e consistência espaço-temporal:

Para os 'hegemonizados' o território adquire muitas vezes tamanha força que combina com intensidades iguais: funcionalidades (recurso) e identidade (símbolo). Assim, para eles literalmente, retomando Bonnemaison e Cambrézy (1996), 'perder seu território é desaparecer'. O território, neste caso, 'não diz apenas à função ou ao ter, mas ao ser' (HAESBAERT, 2004, p. 4, grifo nosso).

Nesse sentido, a formulação das Nações Unidas, citada por Santos (1995), é elucidativa, porque aponta o território como elemento estratégico no reconhecimento dos povos indígenas também pelo outsider.

Comunidades indígenas, povos e nações indígenas são aqueles que, tendo uma continuidade histórica com sociedades pré-in-

\footnotetext{
${ }^{11}$ Um exemplo de mudança ocorrida é o fato de muitos indígenas trabalharem como subempregados em regiões próximas das suas aldeias, ou seja, o território já não constitui o único espaço de subsistência para algumas famílias tsupiniquim. "A aldeia de Caieira Velha surpreende com 45\% da população vivendo de 'empregos'". (CAPTG; CIMI, 1996, p. 24).
} 
vasão e pré-coloniais, consideram-se distintos dos outros setores das sociedades agora prevalecentes naqueles territórios, ou parte deles. Eles formam, no presente, setores não dominantes da sociedade e estão determinados a perceber, desenvolver e transmitir às futuras gerações seus territórios ancestrais e sua identidade étnica, como a base de sua existência continuada como um povo, com seus próprios padrões culturais, instituições sociais e sistemas legais (SANTOS, 1995, p. 315, grifos e tradução nossos).

Paradoxalmente, os que conduziram o processo de expropriação material e simbólica das populações indígenas exigem que estas sejam reconhecidas a partir do seu território e de seus padrões culturais específicos. Todavia, o reconhecimento da identidade étnica indígena a partir da sua condição territorial por agências modernas não significa que isso se traduza em políticas concretas no âmbito do Estadonação. Aliás, as reivindicações indígenas no âmbito do Estado moderno constituem um duplo desafio. O primeiro diz respeito ao direito à autodeterminação e à identidade cultural, que são de caráter coletivo, e o legalismo liberal subjacente ao Estado-nação, que é essencialmente individualista. Sobretudo, exige o reconhecimento de instituições e de ordens jurídicas estranhas ao direito e às instituições do Estado nacional (SANTOS e VILLEGAS, 2001). O segundo refere-se ao atendimento das reivindicações indígenas, implicando um novo ordenamento territorial, porque os direitos ancestrais estão inscritos em um território específico "protegido", no que diz respeito a aspectos essenciais, da intervenção do Estado, confrontando-se radicalmente com a concepção de propriedade privada. Sobre isso, escreve Santos: "Entre todos os direitos coletivos dos povos indígenas, o direito à terra, ao seu território ancestral e seus recursos, é soberano; portanto, a pluralidade legal assume neste caso uma configuração distinta, geo-espacial" (1995, p. 319, tradução nossa). No entanto, na grande maioria das vezes, referenciando-se na lógica da propriedade privada e do mercado, os indígenas são vistos como portadores de áreas subutilizadas, ou seja, há "muita terra para poucos índios". Sobre a questão, comenta ainda Santos: "Num mundo de relações sociais crescentemente desterritorializadas, uma comunidade indígena parece anacrônica, com seu ímpeto hiperterritorial [...]" (SANTOS, 1995, p. 326, tradução nossa).

\section{Histórias Vividas, Histórias Contadas: Reelaborando Território e Territorialidades}

Refletir sobre a história é necessariamente refletir sobre o poder (DEBORD, 1997).

O grito de Werá Kwarí, liderança indígena Guarani: "Somos a favor do progresso da vida e não do progresso da morte!" (MARACCI, 2008), ao repudiar a ação do capital sobre o território do seu povo ${ }^{12}$ e dos seus parentes tupiniquim, traduz a história incansável dos indígenas, nos últimos 42 anos, em terras capixabas.

${ }^{12}$ Os povos tupiniquim e guarani convivem desde 1967, quando uma família Guarani, em busca da Terra Sem Males, chegou ao Espírito Santo. 
As elaborações desse povo sobre suas perdas materiais e simbólicas explicitam a sua capacidade de reelaborar o mundo - o mundo tupiniquim - como estratégia de sobrevivência. Como bem lembra Hissa (2002), a vida é um movimento territorializado e, no movimento de apropriação do espaço - o espaço vivido -, emerge a capacidade do indígena de ressignificar a vida diante da morte; o progresso da morte lhe rouba a vida, compromete os seus ecossistemas e lhe impõe a escassez, alterando profundamente a sua relação com o lugar, configurando, assim, outras formas de territorialidade, não as desejadas, mas as possíveis.

Histórias vividas, histórias contadas constituem um exercício permanente de ressignificação do território do presente tomando como referência o território do passado, não somente por aqueles que o testemunharam, mas também como obra coletiva da comunidade tupiniquim. Naquele tempo (período anterior a 1967), ainda era possível, por meio do território, realizar o modo de vida tupiniquim em todas as suas dimensões; na atualidade, essa experiência ficou extremamente limitada. Esse exercício constante de ressignificação do território do presente, além de ser uma estratégia de sobrevivência, busca alimentar, simbolicamente, o processo de reconstrução do ser indígena das novas gerações, que dispõem de pouca referência material e simbólica, constituindo um movimento de r-existência, de reterritorialização.

Contam os mais velhos que, antes da ARCEL chegar, o seu povo se organizava em 36 aldeias indígenas, espalhadas por 30 mil hectares de florestas. Eram 37, mas Batinga - nome de uma das aldeias - não resistiu à ação da Companhia Ferro e Aço de Vitória (COFAVI), empresa extrativista de siderurgia cujos autofornos eram alimentados, nos anos de 1940, de espécies da Mata Atlântica. As aldeias eram estruturadas por grupos familiares: as famílias eram progressivamente ampliadas pela agregação de outros parentes e afins, aumentando o núcleo residencial. As famílias grandes ocupavam espaços contíguos, divididas em unidades familiares; outras menores se avizinhavam de forma mais espaçada.

Segundo Raffestin, território e espaço não são termos equivalentes, o território se forma a partir da apropriação do espaço: "Ao se apropriar de um espaço, concreta ou abstratamente [...], o ator 'territorializa' o espaço" (1993, p. 143-4). Um exmorador da aldeia Macacos e atual morador de Novo Brasil/Aldeia Pau-Brasil fala sobre o jeito indígena de produção do espaço, referindo-se ao lugar onde viveu parte da sua vida: "Morava muitas famílias, muitas famílias. Era uma casa aqui, outras lá, outras lá, outros lá. Não morava do jeito que tá aqui, não [embolado]. Morava 25 minutos pra lá." (BARCELLOS, 2008). Também uma outra ex-moradora da aldeia de Guaxindiba e atual moradora de Caieiras Velhas afirma:

[...] Nós morava na mata, na mata mesmo [...]. Era mais separado, era mais longe, porque, quando a Aracruz chegou, em 70, aqui pra dentro que começou a trabalhar na área, aqui já faz 40 anos que a Aracruz tá aí. E, então, não existia essa fábrica. Nós vivia numa mata, mas era uma casinha lá, outra lá, outra aqui, era casa mesmo de índio e a nossa casa era de palha, era de tábua, era um barraquinho, então nós morava assim (BARCELLOS, 2007). 
A forma de apropriação tupiniquim do espaço também foi observada pelo cronista Wied-Neuwied, em visita à Província do Espírito Santo, no início do século XIX, quando passava por Comboios: "habitações isoladas de índios, a grande distância uma das outras, esparsas entre capoeiras" (WIED-NEUWIED, 1940, p. 149).

A organização social dos tupiniquim se constituía de dois níveis articulados: um mais restrito à esfera familiar e que também era o núcleo da produção; outro, mais amplo, que abrangia a vida dos parentes, do grupo como um todo e das relações interfamiliares, em que se davam a circulação de produtos e as trocas materiais e simbólicas. "Em suma, as relações sociais entre os tupiniquim encontram-se subjacentes à lógica da economia do grupo" (CAPTG e CIMI, 1996, p. 20). Além das roças itinerantes, havia os plantios no entorno da casa. A intimidade com a floresta e com a agricultura deu aos tupiniquim um profundo conhecimento sobre o uso de variadas sementes e raízes da floresta e também daquelas de uso agrícola: milho, feijão, mandioca e aipim. A lua constituía a referência temporal para as atividades de subsistência. Aqui se fala de um tempo não-suprimido e tampouco subordinado. Fala-se de um tempo que substancia as atividades locais. Os tupiniquim seguiam religiosamente o calendário lunar para escolher as melhores épocas do plantio e também para pescar e mariscar. "Na lua 'escura' [Quarto Minguante ou Lua Nova] faz-se o semeio dos grãos (milho e feijão), assim como o corte de madeira. As pescarias, caçadas e o plantio de manivas são feitos na Lua Crescente. Os caranguejos 'andam' na lua cheia [...]' (CAPTG e CIMI, 1996, p. 19).

A Mata Atlântica, um dos biomas mais ricos em biodiversidade do planeta, presenteava as suas populações com extensa variedade de caças, peixes, ervas e matérias-primas para a confecção do artesanato:

Essa mata, que era formada das coisas que a gente ia fazer: era gamela, era peneira, tapiti, né? Tudo isso vinha dessas matas, e isso sustentava né, porque a gente vendia as coisas que a gente produzia, que a gente fazia. Então, também eram dos rios, era as matas, era caça, tinha muita caça, tinha muito peixe no rio. (MARTINS, CONCEIÇÃO e CLEMENTE, 2007).

As atividades de caça, pesca e coleta eram grifadas pela necessidade da comida e pelo ritual mítico de respeito à natureza. Os tupiniquim mais velhos são grandes estrategistas de caça e de confinamento de animais. Os caçadores indígenas lançavam mão de informações sensoriais (cheiro, cor, sabor) e práticas que orientavam a procura dos alimentos. São saberes acumulados e reciclados de longo tempo.

Da floresta e do mangue também eram extraídas ervas medicinais para os remédios caseiros e matérias-primas para a construção das casas, cuja cobertura era feita com palhas de naiá trançadas. "[...] o que reivindica uma sociedade ao se apropriar de um território é o acesso, o controle e o uso, tanto das realidades visíveis quanto dos poderes invisíveis que o compõem, e que parecem partilhar o domínio das condições de reprodução da vida dos homens [...]" (GODELIER apud HAESBAERT, 2004, p. 69). A terra e tudo o que está nela, que foram recebidos pelas 
atuais gerações por seus antepassados, devem ser usados com muita responsabilidade e preservados para as que virão. Por isso, são populações que conseguiram preservar parte importante dos seus ecossistemas até a década de 1960.

As práticas cotidianas revelavam um espaço em constante processo de negociação interna. Nas aldeias, que são os lugares tupiniquim, havia independência e rotatividade na esfera da produção. Cada família estabelecia seu roçado, mas havia formas coletivas de trabalho dentro das aldeias que contribuíam para a aradura da terra, o plantio e a colheita. A geógrafa inglesa Massey apresenta uma leitura de lugar diferente daquela que o toma como um espaço pré-estabelecido, como uma coerência prestes a ser constrangida por forças externas. "O que é especial sobre o lugar é, precisamente, esse acabar juntos, o inevitável desafio de negociar um aquie-agora [...] e a negociação que deve acontecer dentro e entre ambos, o humano e o não-humano [...]" (2008, p. 203). O lugar compromete vidas, por isso exige ética e responsabilidade ao encarar a eventualidade, o inesperado, e ao lidar com a multiplicidade. Para a autora, o acabar juntos transforma o lugar [a aldeia] em um palco constante de negociação: "O mero fato de termos de continuar juntos, o fato de não podermos (mesmo que queiramos, e isso, em si mesmo, não deve, de forma alguma, ser presumido) purificar espaços/lugares". Nesse acabar juntos, "o que está em questão são os termos do compromisso dessas trajetórias (tanto sociais quanto naturais), essas estórias-até-agora, dentro (e não apenas dentro) daquela conjunturabilidade" (MASSEY, 2008, p. 204).

Massey lembra os códigos implícitos às práticas que se comprometem cotidianamente com o lugar. Essas, por sua vez, também serão estruturantes, porque se conectam a outras práticas, conformando a rede de relações que irão organizar a vida territorial. Os movimentos do lugar influenciam e são influenciados pelos movimentos mais amplos do território, são esses movimentos do cotidiano que vão dar a noção do conjunto, do espaço de uso comunal, que vão substantivar a territorialidade tupiniquim: aldeias próximas estabeleciam, na maioria das vezes, intensa relação de vizinhança, que se aprofundava ainda mais por laços matrimoniais; era, por exemplo, o que acontecia entre as aldeias Guaxindiba, Araribá, Cantagalo e Pau-Brasil. No território, era permitida a mobilidade interna: os tupiniquim que migravam para Caieiras Velhas podiam fazer casa e roça, mas não podiam medir, dizer "aquilo é meu", ou seja, não era permitido nada daquilo que caracterizasse apropriação privada. "Assim se instalavam, moravam e quando desejavam mudar, viajavam para outro local" (BRASIL, 1994, p. 44).

Até 1967, a forma de apropriação do espaço possibilitava o controle sobre a fronteira territorial. As 36 aldeias eram distribuídas por todo o território e tinham como uma das referências espaciais os rios e córregos da região; estavam em áreas de "mata virgem", "mata pura", "cercadas pela mata" ou "no centro da mata" (BRASIL, 1994). Apesar de os nomes das aldeias estarem gravados na memória coletiva, perdem, em meio à paisagem uniformizada pela monocultura de eucalipto, as suas referências de localização. Nem os rios e córregos podem testemunhar a sua existência, porque esses também desapareceram, em consequência das atividades industriais e do plantio de eucalipto em larga escala na região. Com a vinda da agroindústria, o número de aldeias reduziu drasticamente. O processo de dester- 
ritorialização indígena forçou uma nova forma de apropriação do espaço (reterritorialização). As três aldeias que permaneceram (Caieiras Velhas, Pau-Brasil e Comboios) tiveram de aglutinar aqueles que não tinham para onde ir, produzindo uma forte densidade demográfica, em especial na aldeia de Caieiras Velhas. Essa nova forma de conformação do espaço vai interferir sobremaneira no exercício da sua territorialidade. ${ }^{13} \mathrm{~A}$ territorialidade tupiniquim, mesmo com a dimensão física do território bastante reduzida, marcará a sua alteridade; é grifada ainda pelo alto grau de conhecimento das gerações mais velhas sobre os seus ecossistemas.

\section{Apropriação de Terras pelo Capital e a R-existência Tupiniquim}

Com ingredientes modernos e desenvolvimentistas, a relação entre os povos tradicionais do Espírito Santo e a ARCEL reedita a história colonial - alguns a chamariam de relação pós-colonial, ou seja, formas de dominação que caracterizaram o período colonial, reelaboradas e transportadas para a contemporaneidade - e impõe às comunidades indígenas perdas materiais e simbólicas irreparáveis (BARCELLOS e FERREIRA, 2007). A diferença é que, nesse acontecimento da atualidade, o colonizador estabeleceu uma prévia aliança com sujeitos internos (Estado, lideranças políticas e empresariais nacionais e estaduais), que deu suporte ao processo de invasão e ocupação de terras.

A empresa chegou nos tempos de ditadura militar, na gestão do presidente Costa e Silva (1967-9). Segundo estudos, foi um dos períodos de maior rigor da ditadura, o que impediu que os indígenas esboçassem qualquer reação ao seu processo de expropriação territorial. "Época de desmandos, censura, tortura, cerceamento das liberdades e direitos, negócios obscuros e desinformação generalizada" (FASE-ES, 2002, p. 8). Momento em que se conjugavam diversos fatores: a forte concentração de terras e de riquezas, a exploração de mão-de-obra desqualificada e barata, uma economia baseada na exportação de matéria-prima bruta e o uso da força contra os habitantes das terras:

Analisando este contexto de forma generalizada, pode-se então afirmar que não há ruptura entre seu aparecimento e a pior das nossas tradições terceiro-mundistas: a formação de uma elite que une interesses financeiros à violência de um Estado ditatorial, que privilegia grupos econômicos [...], que se instala [...] com todas as prerrogativas e regalias (FASE-ES, 2002, p. 8).

A apropriação do espaço pelo capital internacional, nos países do Sul, exigiu uma "arrumação" de informações institucionais e políticas, paralelamente à produção de um espaço artificial, onde sujeitos locais, por se colocarem como obstáculos ao desenvolvimento econômico, foram transformados em ausentes. No caso do território indígena, estranhamente um relatório técnico ${ }^{14} \mathrm{o}$ identificava como

\footnotetext{
${ }^{13}$ Raffestin define territorialidade como "o conjunto de relações estabelecidas pelo homem enquanto pertencente a uma sociedade, com a exterioridade e a alteridade através do auxílio de mediadores ou instrumentos" (apud HAESBAERT, 2004, p. 87).
} 
"terras improdutivas e parcialmente desabitadas, tecnicamente apropriadas para o plantio da monocultura de eucalipto [...] uma macabra representação de lugares despidos de vida natural e social" (CICCARONE e SCARIM, 2003, pp. 1-2).

Populações indígenas, comunidades quilombolas, pequenos proprietários e organizações sociais buscaram denunciar os acontecimentos da época, questionando a procedência das terras sob o controle da ARCEL. Contudo, em um contexto de repressão política embalado pelo afã desenvolvimentista, suas vozes pouco ecoaram. Somente a partir de 2002, com a instalação pela Assembleia Legislativa do Espírito Santo de uma Comissão Parlamentar de Inquérito para apurar possíveis irregularidades da empresa em processos de licenciamentos ambientais, acontecimentos graves envolvendo a apropriação ilegal de terras pela empresa vieram à tona. Os autos da CPI revelaram que alguns de seus funcionários, atualmente aposentados, atuaram como "laranjas" na compra de terras devolutas do Estado, entre as quais estão grandes parcelas do território indígena. De acordo com Fanzeres (2005), 22 mil hectares de terras devolutas (são compreendidas como terras devolutas também aquelas habitadas pelos indígenas) foram repassados à ARCEL por meio de 29 exfuncionários da empresa, alguns dos quais funcionários aposentados atualmente. Sobre isso, Salomão comenta que "como os requerimentos eram realizados diretamente junto ao poder público, muitas vezes as famílias só vinham a saber o que tinha ocorrido quando já não possuíam mais o terreno" (2006, p. 63). As estratégias usadas pela empresa foram as mais variadas. Segundo a FASE-ES (2003, p. 8), "[...] o cenário de privilégio acabou por criar uma verdadeira 'caixa preta' onde a forma pela qual as terras da empresa foram adquiridas e seu violento processo de legitimação junto às populações tradicionais permanecem até hoje obscuros". Longe de seguir um padrão ético, a ARCEL foi rapidamente tomando posse de territórios de uso comunal de populações indígenas, no município de Aracruz, e de comunidades quilombolas, nos municípios de São Mateus e Conceição da Barra. Seguem depoimentos de lideranças tupiniquim sobre a questão:

A Aracruz chegava pagando pro posseiro ou pro índio do lugar, pagando pouco ou nada, eles ficavam com medo. Você vendia ou eles tomavam isso aí de você e ficava sem nada. Aí os índios foram se afastando, saindo, foram pra cidade, vieram pra Caieiras Velhas, foram pra Barra do Sahy, Riacho. A Aracruz chegou arrebentando tudo, trouxe dois tratores e um correntão, e ia levando tudo que tinha pela frente, encontrávamos tudo quanto é bicho morto lá, ai foram acabando com as matas, os pássaros, secaram os córregos (Alexandre Sezenando) (BRASIL, 1994, p. 67).

\footnotetext{
${ }^{14}$ A Empresa de Consultoria Econômica e Engenharia Industrial S.A. (ECOTEC) foi contratada pelo governo do Estado e por empresários (nacionais e internacionais que tinham interesse em implantar uma agroindústria de celulose), em 1967, para elaborar o estudo "Potencial Florestal e Silvicultura no Espírito Santo". O estudo constatou que o município de Aracruz dispunha de uma grande quantidade de terras subutilizadas. Eram as terras habitadas pelos tupiniquim.
} 
Quando a Aracruz chegou aqui e botou eles [os primos] pra fora... ela chegou invadindo. Quando ela chegou, eles ficaram com medo e largaram a terra deles e foram embora. Ela chegou com um monte de tratô e passou em cima das casinhas deles. As casinha era de palha, barreada, que eles morava. Aí, tem os meus primos que têm vontade de retornar pra dentro da aldeia de novo (BARCELLOS, 2005).

Passados 42 anos da sua chegada do projeto agroindustrial da ARCEL, na atualidade, ela constitui a maior proprietária de terras na história do Espírito Santo, com aproximadamente 170.000 hectares. Todavia, se por um lado ela amplia cada vez mais o seu patrimônio fundiário, por outro tem que lidar, desde 1970, com vários focos de resistência à sua expansão. As manifestações vêm de todos os cantos do Estado: comunidades quilombolas, movimentos camponeses, movimentos de direitos humanos, ONGs socioambientais, entre tantos outros. No caso particular dos indígenas, os acontecimentos inesperados no final dos anos 1960, somados ao fato de estarem vivendo num período de Ditadura Militar, dificultaram a formação de um movimento coletivo de resistência às investidas da empresa. Por isso, os primeiros anos da década de 1970 serviram para que os indígenas compreendessem a complexidade dos eventos ocorridos e acumulassem forças para travar as batalhas de retomada do seu território.

O primeiro movimento coletivo dos tupiniquim pela retomada do seu território de que se tem notícia ocorreu na segunda metade da década de 1970, quando reivindicaram do Estado brasileiro, por meio da FUNAI, o seu reconhecimento como etnia tupiniquim. Para Santos, a luta indígena na América Latina por seus territórios e pelo reconhecimento étnico é emancipatória, porque se baseia no reconhecimento da diferença. A relevância da dimensão cultural no "multiculturalismo emancipatório" reside no fato de que nela pode estar o antagonismo à lógica capitalista. Se o capitalismo transnacional deseja transformar tudo em mercadoria, inclusive a cultura, "[...] é precisamente onde o trabalho, diferenciado e não 'abstrato' está a ser transformado em mercadoria que o cultural se torna, de novo, político" (SANTOS, 2004, p. 25). Nesse sentido, a luta dos tupiniquim pelo seu reconhecimento étnico constitui, já no início dos anos 1970, um importante foco de resistência à lógica capitalista, porque vai procurar demarcar limites da intervenção do capital no espaço local:

Nesse processo de territorialização da luta, os Tupiniquim [...] carregam consigo, ressignificam e socializam suas territorialidades (de matriz indígena), recuperadas (o pré-existente como fonte de direito), re-elaboradas, reinventadas, articulando temporalidades de suas vivências e de suas ancestralidades no percurso da luta (MARACCI, 2008, pp.15-6).

No entanto, apesar das novas alianças que se desenhavam, muitos aspectos fragilizavam as suas reivindicações, e um deles era a inexistência de um aparato le- 
gal que reconhecesse, explicitamente, o seu direito coletivo à terra. A elaboração da nova Constituição Federal do Brasil, em 1988, estabeleceu um marco para os povos indígenas no Brasil. A nova Constituição consagrou o caráter pluriétnico e multicultural da nação brasileira, ao mesmo tempo em que outorgou uma série de direitos, reconhecendo, juridicamente, a existência indígena como um sujeito coletivo, culturalmente diferente do restante da sociedade nacional.

Em 1996, as lideranças indígenas tupiniquim (e também guarani) deflagraram a Campanha Internacional pela Ampliação e Demarcação das Terras Indígenas de mais 13.579 hecrares. ${ }^{15}$ Essa campanha foi um divisor de águas da luta indígena no Espírito Santo. A partir da sua deflagração, organizações não-governamentais da Europa ficaram sabendo dos impactos gerados nos países do Sul pela indústria de celulose, matéria-prima do papel consumido em especial pelos Estados Unidos e pelos países da Europa: "papel para o Norte, monocultura para o Sul". A luta indígena no Espírito Santo denunciava a perversa relação entre produção e consumo, ou seja, para aumentar a acumulação de capital e o elevado padrão de consumo de papel dos países do Norte (países desenvolvidos ou países do Primeiro Mundo), populações do Sul eram expropriadas dos seus territórios. ${ }^{16}$

Diante da morosidade do Estado brasileiro em reconhecer o seu direito ao território tradicional e diante do novo contexto de apoio internacional e local, os indígenas, em março de 1998, deflagraram o seu segundo movimento de autodemarcação territorial, resultando na demarcação de 2.571 hectares, tamanho bem aquém do reivindicado. Com o passar do tempo, foram percebendo que, quanto mais longe da terra, mais longe ficariam da sua condição indígena, na medida em que as novas gerações já não mais sabiam o que era trabalhar com a terra e desconheciam práticas culturais importantes que possibilitavam a reposição da sua identidade indígena. Por isso, o lema do terceiro processo de autodemarcação foi "Nossa terra, nossa liberdade", deflagrado no início de 2005. Diferente dos outros dois movimentos anteriores de autodemarcação, que tinham como estratégia a demarcação física do território, dessa vez as ações consistiam, além da autodemarcação, na reconstrução de aldeias extintas:

Essa última demarcação foi a mais difícil, eu fiquei cinco dias no mato e eu trabalhava e não tive medo que me mandasse embora. Enfrentamos bicho, frio, enfrentamos água, ficamos atolados até o pescoço. Até que a gente não conseguir a terra a gente não vai ter sossego. Ela (a Aracruz) invadiu a nossa terra e nossas matas, ela derrubou as nossas matas, ela tem que devolver isso aí pra nós (COMISSÃO DE MULHERES, 2007).

\footnotetext{
${ }_{15}$ Parece relevante informar que o primeiro movimento de autodemarcação de suas terras, deflagrada na segunda metade da década de 1970, resultou na primeira demarcação oficial de uma área de 4.492 hectares, fragmentada, tamanho menor do que o reivindicado.

${ }^{16}$ Segundo Overbeek (apud BARCELLOS e FERREIRA, 2007), dos 365 milhões t/ano de papel produzidos no mundo, em 2005 a Europa e a América do Norte consumiram, juntas, 77\%; enquanto a América Latina consumiu 6\%, e a África, 2\%. Em 2006, de acordo com o autor, enquanto um canadense consumiu 293 quilos/ano de papel, um latino-americano consumiu o correspondente a 35 quilos/ano, e um africano, 5 quilos/ano.
} 
A ocupação aconteceu em junho de 2005 e aldeias extintas começaram a ser reconstruídas. Escreve Maracci: "Mutirões de construção das casas e de arrecadação de mudas de árvores nativas e frutíferas foram feitos, configurando um processo conjunto de reterritorialização indígena" (2008, p. 206). Continua a autora: "[...] projetam a reconversão das terras autodemarcadas de modo a recriar as condições de vida de cada povo, cada um a seu modo [...]." (MARACC, 2008, p. 206). Em outubro de 2005, o complexo agroindustrial da ARCEL foi ocupado por mais de 500 índios. A ocupação era parte das estratégias organizadas para chamar a atenção da opinião pública e do governo brasileiro, buscando acelerar a demarcação do território. A ocupação durou dois dias e teve um forte conteúdo simbólico, porque alguns daqueles que ali estavam nasceram na aldeia Macacos e, depois da chegada da empresa, nunca mais puderam voltar àquele lugar. A Comissão de Caciques elaborou uma nota pública sobre o acontecimento:

Aracruz Celulose ocupada! Ocupamos o complexo de três fábricas da Aracruz Celulose no município de Aracruz, para manifestar publicamente sobre a retomada das nossas terras [que] estão invadidas por esta multinacional. As suas fábricas, hoje por nós ocupadas, estão construídas sobre a nossa antiga aldeia Macacos. Responsabilizamos a Aracruz Celulose pelos principais problemas que vivemos durante todos estes anos. Ela é responsável pela destruição dos rios, das matas, da terra e a quase destruição da nossa cultura e do nosso modo de vida. Nosso movimento é para protestar e comunicar ao Governo Federal que não aceitamos as interferências e as imposições da Aracruz Celulose no processo de regularização das nossas terras; para cobrar do sr. Ministro da Justiça urgência na expedição da portaria demarcatória das nossas terras [...]. Nossa terra, nossa liberdade! (COMISSÃO DE CACIQUES, 2005).

Com os fatos ainda frescos na memória, as mulheres falam sobre suas próprias participações no dia da ocupação. "Na ocupação da fábrica, a presença das mulheres e das crianças impediu que a Aracruz atacasse os índios". E ainda: "Então, somos ou não somos fortes? O povo indígena tem que conscientizar que o nosso conhecimento vem do berço, desde que somos pequenos, vem das nossas raízes, é isso que nos dá força, que torna a gente forte" (COMISSÃO DE MULHERES, 2007). Como resposta às ações dos índios, a ARCEL iniciou uma campanha de desmoralização dos tupiniquim no estado, estimulando a discriminação étnica. Segue o depoimento de uma liderança indígena:

O que tá acontecendo agora é assim, as pessoas estavam falando lá nos comércios que os índios não eram mais índios, como se fôssemos ladrões, e que, em qualquer lugar que a gente for, a gente ia fazer bagunça, aí, eles falaram nos co- 
mércios, né? Muitos começou a vigiar dizendo que os índios podia roubar alguma coisa nos supermercados, pra que os índios não roubasse alguma coisa. Aí, a gente teve discriminação também nas escolas. Os professores falavam que a gente não era índio e começavam a fazer alguns comentários, principalmente minha sobrinha. Uns tempos aí, teve discriminação nas escolas de um professor. Ela voltou para casa chorando, aí os pais dela precisou ir lá para conversar com eles. Aí, a discriminação é assim, muita chacota, alguma coisa assim, os pais vão lá, aí, eles não têm como falar com índios mais velhos e, aí, eles descontam nos filhos, né? Nas escolas (MARTINS, CONCEIÇÃO e CLEMENTE, 2007).

Como resultado de toda essa campanha difamatória, foi criada uma forte resistência à presença indígena entre os moradores do município de Aracruz, onde se localizam as aldeias. Índios eram ameaçados, impedidos de entrar em supermercados, crianças eram constrangidas nas escolas. Estranhamente, uma população que testemunhou a presença indígena naquela região aderia, com força, ao discurso da empresa de que ali nunca haviam existido índios. Diria Bourdieu que esse é um imaginário social alimentado pelo poder material e carregado por um forte poder simbólico: "O poder de constituir o dado pela enunciação, de fazer ver e fazer crer, de confirmar ou de transformar a visão do mundo, e, deste modo, a ação sobre o mundo [...] poder quase mágico que permite obter o equivalente daquilo que é obtido pela força (física ou econômica)" (2007, p. 10). Nesse caso, os sistemas simbólicos, que alimentam o poder simbólico, constituem instrumentos por excelência da integração, tornando possível o consenso sobre o sentido do mundo social, condição sine qua non para a reprodução da ordem social: "a integração 'lógica' é a condição da integração 'moral'". Na teoria crítica, os chamados "sistemas simbólicos" (BOURDIEU, 2007) são vistos como instrumentos da ideologia - estruturados e estruturantes - de conhecimento e de comunicação, assegurando a dominação de uma classe sobre a outra (violência simbólica):

A cultura dominante contribui para a integração real da classe dominante [...]; para a integração fictícia da sociedade no seu conjunto, portanto, à desmobilização (falsa consciência) das classes dominadas; para a legitimação da ordem estabelecida por meio do estabelecimento das distinções (hierarquias) e para a legitimação dessas distinções. Esse efeito ideológico, produz-lo a cultura dominante, dissimulando a função de divisão na função de comunicação: a cultura que une [...] e também a cultura que separa [...] e que legitima as distinções compelindo todas as culturas (designadas como subculturas) a definirem-se pela sua distância em relação à cultura dominante (BOURDIEU, 2007, pp. 10-1). 
O poder simbólico dominante ensina que o objetivo não é expulsar o homem da vida social, ao contrário, é geri-lo, controlá-lo em suas ações para que seja passível de uso. O objetivo é, ao mesmo tempo, econômico e político: "[...] aumento do efeito do seu trabalho, isto é, tornar os homens força de trabalho, dando-lhes uma utilidade econômica máxima, e a diminuição da sua capacidade de revolta e resistência de luta, neutralizando os efeitos de contra-poder [poder simbólico dos dominados]" (MACHADO, 2004, p. XVI), tornando-os homens dóceis politicamente, ou seja, o objetivo é aumentar a força econômica e reduzir a força política.

Para Bourdieu, a destruição do poder de imposição simbólica radicado no desconhecimento supõe a tomada da consciência do arbitrário, quer dizer, "[...] a revelação da verdade objetiva e o aniquilamento da crença: é na medida em que o discurso heterodoxo destrói as falsas evidências da ortodoxia [...]" (2007, p. 15), que, ao mesmo tempo, permite aflorar o poder simbólico da mobilização, da subversão, o poder potencial das classes dominadas. No entanto, a oportunidade do discurso heterodoxo tem sido cada vez mais aniquilada, não só pelo fato de ser colocado em xeque aquilo que é essencial à sociedade moderno-capitalista - o mito do progresso/desenvolvimento econômico -, mas, sobretudo, pelos instrumentos utilizados, cada vez mais poderosos. A homogeneização do "sujeito" pelos meios de comunicação de massa, criando uma coletividade subordinada, tem sido um dos principais empecilhos para as populações indígenas que também se veem envolvidas nesse jogo da massificação. As práticas de racismo incentivadas pela empresa assumiram tamanha gravidade que o Ministério Público Federal interveio com uma ação contra a empresa.

Diante das investidas da empresa e da insistência da luta indígena, em meio a pressões locais, nacionais e internacionais, preocupado com os desdobramentos dos acontecimentos na região, o Ministro da Justiça resolveu demarcar a área reivindicada, 11.009 hectares, o que ocorreu em setembro de 2007. No entanto, até a presente data, a demarcação não foi homologada pela Presidência da República. A partir dessa última demarcação, os tupiniquim (em conjunto com os guarani) estão de posse de 18.072 hectares, representando 60,24\% do território possuído até a década de 1960.

\section{Conclusão}

O desdobramento da luta tupiniquim (e também dos guarani) tem sido a recuperação gradual do seu território, levando a empresa a perder parte de "suas terras", senão significativas em extensão/quantidade, significativas do ponto de vista político e geográfico. Do ponto de vista político, o que é visto a cada demarcação de uma nova parcela do território indígena, confirmam-se as denúncias de que a ARCEL se apropriou injustamente de terras indígenas, gerando sempre um novo processo de desgaste público da sua imagem; do ponto de vista geográfico, visto que as terras indígenas demarcadas estão localizadas no entorno da sua planta industrial e são, na maioria das vezes, as áreas que guardam as reservas hídricas que garantem o seu abastecimento. O conteúdo da luta indígena no Espírito Santo tem possibilitado aos indígenas colocar em xeque o processo de acumulação capitalista, quando inserem na pauta dos movimentos sociais e da sociedade civil a 
discussão sobre o modelo hegemônico de desenvolvimento em curso. A luta pela reapropriação territorial possibilita a reapropriação da sua identidade e alteridade indígenas. Também the dá oportunidade de se colocar como um importante sujeito histórico: "O sujeito da história só pode ser o ser vivo produzindo a si mesmo, tornando-se mestre e possuidor de seu mundo que é a história e existindo como consciência de seu jogo" (DEBORD, 1997, p. 50). Uma moradora da aldeia Irajá e coordenadora da Comissão de Mulheres Indígenas Tupiniquim e Guarani afirma o significado da luta indígena no Espírito Santo:

Nós, povos indígenas, percorremos um longo caminho de reconstrução dos nossos territórios e das nossas comunidades. Com essa história firmemente agarrada por mãos coletivas, temos a certeza de que rompemos com o nosso triste passado e nos lançamos com confiança em direção ao futuro. Apesar do peso da velha história inscrita pelas classes dominantes deste país, na nossa cultura, nas suas práticas políticas e econômicas e nas suas instituições de Estado, já lançamos o nosso grito de guerra; colocando as bases de uma nova história, uma grande história: nós povos agora vamos lutar por outros 500! [...] A nossa luta indígena é uma homenagem aos inúmeros heróis que tombaram guerreando ao longo de cinco séculos. A nossa luta é para os nossos filhos e netos, povo livre numa terra livre (ALEIDA apud JESUS, 2002, p. 83).

Os tupiniquim revelam uma disposição de luta e uma esperança de transformar uma realidade de escassez em uma realidade como aquela de outrora, quando dispunham do seu território e ecossistemas. Nessa pulsão de vida, mulheres e homens vão "r-existindo" e reafirmando as suas identidades e a alteridade tupiniquim. 


\section{Referências Bibliográficas:}

ARCEL. Sumário do plano de manejo Florestal da Aracruz Celulose S.A. Aracruz, 2006. Disponível em http://www.aracruz.com.br/doc/pdf/ sumario_ pmf_2006.pdf. Acesso em 3 de maio. 2008.

Plano de manejo florestal da Aracruz Celulose: unidade Guaíba.

Aracruz, 2007. Disponível em http://www.aracruz.com.br/doc/pdf/resumo_publi co_plano_de_manejo_florestal_guaiba_2007.pdf. Acesso em 23 de janeiro. 2008.

Relatório anual 2007. A Gazeta. Vitória, 16 de janeiro. 2008. pp. 13-9.

BARCELLOS, Gilsa Helena. Primeira entrevista grupal realizada com lideranças tupiniquins da Aldeia Irajá e da Aldeia Pau-Brasil. Aracruz, 26 de agosto. 2005. BARCELLOS, Gilsa Helena Barcellos. Desterritorialização e R-existência Tupiniquim: mulheres indígenas e o complexo agroindustrial da Aracruz Celulose. Minas Gerais, Tese de Doutorado, Programa de Pós-Graduação em Geografia, UFMG, 2008, mimeo. e FERREIRA, Simone Batista. Mulheres e eucalipto: histórias de vida e resistência. Brasil, Montevidéo: WRM, n. 11, 2007. Coleção sobre plantações. BECHARA, Evanildo. Moderna gramática portuguesa. 37 ed. Rio de Janeiro: Lucerna, 2006.

BONNEMAISON, Joel e CAMBRÈZY, Luc. Le lien territorial: entre frontières et identités. Géographies et Cultures (Le Territoire), n. 20. Paris: L’Harmattan, 1996. BOURDIEU, Pierre. O poder simbólico. Trad. Fernando Thomaz. 10 ed. Rio de Janeiro: Bertrand Brasil, 2007.

BRAGA, Elda Firmino. O romance de testemunho e a reescritura da história.

Disponível em www.filologia.org.br/ivcluerj-sg/anais/ii/completos/mesas/8/ elda firmo braga.pdf. Acesso em 20 de agosto. 2007.

BRASIL. Ministério da Justiça. Relatório final de reestudo da identificação das terras indígenas Caieiras Velhas, Pau-Brasil e Comboios. Brasília, 1994.

CICCARONE, Celeste e SCARIM, Paulo. A Aracruz Celulose e a questão indígena. Rio de Janeiro: Tempo e Presença, v. 330, 2003, pp. 31-6.

CAPTG e CIMI. Campanha internacional pela ampliação e demarcação das terras indígenas Tupinikim e Guarani. Aracruz: CIMI, 1996.

COMISSÃO DE CACIQUES. Carta aberta à população. Aracruz, 6 de outubro. 2005. COMISSÃO DE MULHERES INDÍGENAS TUPINIQUIM E GUARANI. Reunião.

Comboios, Aracruz, 21 de março. 2007.

DEBORD, Guy. A sociedade do espetáculo. Trad. Estela dos Santos Abreu. Rio de Janeiro: Contraponto, 1997.

FANZERES, Anna. Temas conflituosos relacionados à expansão da base florestal plantada e definição de estratégias para minimização dos conflitos. Brasília: Ministério do Meio Ambiente, 2005, 261 p.

FASE-ES. Violação de direitos econômicos, sociais, culturais e ambientais na monocultura de eucalipto: a Aracruz Celulose e o Estado do Espírito Santo/Brasil. 
Vitória: FASE, 2002. 38 f. Disponível em www.fase.org.br. Acesso em 23 de janeiro. 2007.

GODELIER, M. L'idéel et le materiel. Paris: Fayard, 1984.

GUATARRI, Félix. Caosmose: um novo paradigma estético. Trad. Ana Lúcia de Oliveira e Lúcia Cláudia Leão. 3 ed. São Paulo: Editora 34, 2000.

HAESBAERT, Rogério. O mito da desterritorialização: do "fim dos territórios" à multiterritorialidade. Rio de Janeiro: Bertrand Brasil, 2004.

Desterritorialização: entre as redes e os aglomerados de exclusão. In:

CASTRO, Iná Elias; GOMES, Paulo César da Costa e CORRÊA, Roberto Lobato (orgs.). Geografia: conceitos e temas. Rio de Janeiro: Bertrand Brasil, 2005, pp. 165-205.

HISSA, Cássio Eduardo Viana. A mobilidade das fronteiras: inserções da geografia na crise da modernidade. Belo Horizonte: UFMG, 2002.

HOBSBAWM, Eric J. Nações e nacionalismo desde 1780: programa, mito e realidade. Trad. Maria Celia Paoli e Anna Maria Quirino. Rio de Janeiro: Paz e Terra, 1990.

IANNI, Octávio. A sociedade global. Rio de Janeiro: Civilização Brasileira, 2003. JESUS, Nilma do Carmo. O resgate da cultura Tupinikim. Espírito Santo, Monografia de Graduação. Departamento de Educação, Faculdade de Ciências Humanas de Aracruz (FACHA), 2002, mimeo.

LIST, Friedrich. The national system of political economy. Londres: 1885.

MACHADO, Roberto. Introdução: por uma genealogia do poder. In: FOUCAULT, Michel. Microfísica do poder. Trad. Roberto Machado. 20 ed. Rio de Janeiro: Graal, 2004. pp. vii-xxiii.

MARACCI. Marilda. Progresso de morte, progresso de vida: a reterritorialização conjunta dos povos Tupiniquim e Guarani em luta pela retomada de seus territórios. Niterói, Tese de Doutorado. Programa de Pós-Graduação em Geografia, UFF, 2008. mimeo.

MARTINS, Edna; CONCEIÇÃO, Ana Lúcia da e CLEMENTE, Ana. Entrevista com mulheres indígenas e quilombolas. Comunidade de São Domingos, Conceição da Barra (ES), 4 de agosto. 2007. [A pedido do Movimento Mundial de Defesa das Florestas Tropicais (WRM), com sede no Uruguai].

MASSEY, Doreen. Pelo espaço: uma nova política da espacialidade. Trad. Hilda Pareto Maciel e Rogério Haesbaert. Rio de Janeiro: Bertrand Brasil, 2008.

MIGLIAZZA, Ernest C. Linguistic prehistory and the refuge model in Amazônia. In: PRANCE, Ghillean T. Biological diversification in the tropics. New York: Columbia University Press, 1982.

MILL, J. S. Utilitarianism, liberty and representative government. Londres:

Popular, 1910.

MORAES, Neida Lúcia. Atlas escolar do Espírito Santo. Vitória: Secretaria de Estado da Educação e Cultura do Espírito Santo, 1986.

NANDY, Ashis. Estado. In: SACHS, Wolfgang. Dicionário do desenvolvimento: guia para o conhecimento. Trad. Vera Lúcia M. Joscelyne; Susana de Gyalokay e Jai-me A. Clasen. Petrópolis: Vozes, 2000, pp. 84-97. 
PORTO-GONÇALVES, Carlos Walter. Da geografia às geo-grafias: um mundo em busca de novas territorialidades. México: CLACSO, 2001.

. A reinvenção dos territórios: a experiência latino-americana e caribenha. En publicación: Los desafíos de las emancipaciones en un contexto militarizado. Ceceña, Ana Esther. CLACSO, Consejo Latinoamericano de Ciencias Sociales, Ciudad Autónoma de Buenos Aires, 2006, pp. 151-97. RAFFESTIN, Claude. Repères pour une théorie de la territoirialité humaine. In: DUPUY, Gabriel (org.). Réseaux territoriaux. Caen: Paradigme, 1988. Ática, 1993. Por uma geografia do poder. Trad. Maria Cecília França. São Paulo: SALOMÃO, Juliana Freitas. O outro lado do desenvolvimento: o bairro São Benedito (Vitória/ES) e os impactos urbanos da agroindústria de celulose. Rio de Janeiro: Dissertação de Mestrado. Programa de Pós-Graduação em Planejamento Urbano e Regional, UFRJ, 2006. mimeo.

SÁNCHES, Beatriz Eugênia. El reto del multiculturalismo jurídico. La justicia de la sociedad mayor y la justicia indígena. In: SANTOS, Boaventura de Sousa; VILLEGAS, Maurício García. El caleidoscopio de las justicias en Colombia. Bogotá: Siglo del Hombre, 2001.

SANTOS, Boaventura de Sousa. Globalization, nation-states and the legal field: ancient grievances and new solidarities: the law of indigenous peoples. Toward a new common sense: law, science and politics in the paradigmatic transition. New York: Routdlege, 1995, pp. 313-26.

. A crítica da razão indolente: contra o desperdício da experiência. 3 ed. São Paulo: Cortez, 2001.

. Por uma concepção multicultural de direitos humanos. Reconhecer para libertar: os caminhos do cosmopolitismo multicultural. Porto: Afrontamento, 2004, pp. 331-56.

SANTOS, Boaventura de Sousa e VILLEGAS, Maurício García. El caleidoscopio de las justicias en Colombia. Bogotá: Siglo del Hombre, 2001

SANTOS, Milton. O retorno do território. In: SANTOS, Milton e SOUZA, Maria Adélia de e SILVEIRA, Maria Laura. Território: globalização e fragmentação. São Paulo: Hucitec, 1996, pp. 15-20.

SCHIMIT, Graham. Russia, ethnoregionalism and the politics of federation. Ethnic and racial studies, v. 19, 1996, n. 2, pp. 391-410.

SCHMITZ, Pedro Ignácio. Migrantes da Amazônia: a tradição tupiguarani. Arqueologia do Rio Grande do Sul, Brasil. 2. ed. São Leopoldo: Instituto Anchietano de Pesquisas - UNISINOS, 2006, pp. 31-64. Disponível em www.anchietano. unisinos.br/publicacoes/documentos/documentos05.pdf. Acesso em 13 de dezembro. 2006.

SOUSA FILHO, Carlos Frederico Marés de. Multiculturalismo e direitos coletivos. In: SANTOS, Boaventura de Sousa. Reconhecer para libertar: os caminhos do cosmopolitismo multicultural. Porto: Afrontamento, 2004, pp. 57-83.

SOUZA, Marcelo José Lopes de. O território: sobre espaço e poder, autonomia e desenvolvimento. In: CASTRO, Iná Elias; GOMES, Paulo César da Costa e COR- 
RÊA, Roberto Lobato (orgs.). Geografia: conceitos e temas. Rio de Janeiro:

Bertrand Brasil, 2005.

WIED-NEUWIED, Maximiliano de. Viagem ao Brasil. Trad. Edgard Sussekind de Mendonça e Flávio Poppe de Figueiredo; refundida e anotada por Oliveira Pinto. São Paulo: Companhia Editora Nacional, 1940.

Recebido em 03 de agosto de 2009.

Aceito para publicação, em 10 de outubro de 2009. 